\title{
AC 2011-1097: A 2-YEAR CASE STUDY: ASSESSING THE IMPACT OF ACTIVE LEARNING ON ELEMENTARY SCHOOL STUDENTS DURING GK-12 OUTREACH ADMINISTERED ENERGY CLUBS
}

\author{
Lynn Albers, North Carolina State University
}

Lynn Albers received her B.S. in Mathematics with a minor in Music from MIT in 1992 and her M.S. in Mechanical Engineering with a minor in Nuclear Engineering from Manhattan College in 1996. After working for Nortel Networks and the North Carolina Solar Center, Lynn matriculated at North Carolina State University where she is a Ph.D. candidate in Mechanical Engineering. Her dissertation spans the Colleges of Engineering and Education and is the first of its kind for NCSU.

\section{Laura Bottomley, North Carolina State University}

Laura Bottomley received a B.S. in Electrical Engineering in 1984 and an M.S. in Electrical Engineering in 1985 from Virginia Tech. She received her Ph D. in Electrical and Computer Engineering from North Carolina State University in 1992.

Dr. Bottomley worked at AT\&T Bell Laboratories as a member of technical staff in Transmission Systems from 1985 to 1987, during which time she worked in ISDN standards, including representing Bell Labs on an ANSI standards committee for physical layer ISDN standards. She received an Exceptional Contribution Award for her work during this time.

After receiving her $\mathrm{Ph}$ D., Dr. Bottomley worked as a faculty member at Duke University and consulted with a number of companies, such as Lockheed Martin, IBM, and Ericsson. In 1997 she became a faculty member at NC State University and became the Director of Women in Engineering and K-12 Outreach. She has taught classes at the university from the freshman level to the graduate level, and outside the university from the kindergarten level to the high school level.

Dr. Bottomley has authored or co-authored 37 technical papers, including papers in such diverse journals as the IEEE Industry Applications Magazine and the Hungarian Journal of Telecommunications. She received the President's Award for Excellence in Mathematics, Science, and Engineering Mentoring program award in 1999 and individual award in 2007. She was recognized by the IEEE with an EAB Meritorious Achievement Award in Informal Education in 2009 and by the YWCA with an appointment to the Academy of Women for Science and Technology in 2008. Her program received the WEPAN Outstanding Women in Engineering Program Award in 2009. Her work was featured on the National Science Foundation Discoveries web site. She is a member of Sigma Xi, past chair of the K-12 and Precollege Division of the American Society of Engineering Educators and a Senior Member of the IEEE.

\section{Amber C. Spolarich, North Carolina State University}

Amber Spolarich is currently a senior at North Carolina State University majoring in chemical engineering with a concentration in green chemistry. She has worked with outreach programs through the university that have placed her in local public schools to act as a resource for science, math, and engineering related courses in the hopes of elevating excitement for learning in K-12 classrooms. She has also conducted research in conjunction with the Vanderbilt Instruction in Biomedical Engineering for Secondary science (VIBES) program which aids high school teachers in bringing engineering education into their classrooms

\section{Miss Clair Ellen-Ann Wilson, RAMP-UP}

I work with RAMP-UP as an Undergraduate Fellow.

\section{Miss Laura Elizabeth Ganson, North Carolina State University}

Laura Ganson is majoring in Secondary Science Education with a concentration in Physics. She also works with RAMP-UP as an Undergraduate Fellow. 


\title{
A 2-Year Case Study: Assessing the Impact of Active Learning on Elementary School Students During GK-12 Outreach Administered Energy Clubs
}

\begin{abstract}
Active learning during GK-12 outreach administered Energy Clubs can positively affect students in grades 3-5 by improving their understanding of technology, what engineers do, the engineering design process, and how to improve a windmill. Last year, the impact was assessed through a pretest and posttest from the Engineering is Elementary workbook, "Catching the Wind."'[2] After completing one activity where the students built windmills out of milk cartons, there were positive improvements ranging from 3\% to $8 \%$ in their understanding of technology, what engineers do and the engineering design process. Significant gains $(\mathrm{p}<0.05)$ were made in understanding how to improve a windmill where all the clubs had double-digit growth with an overall improvement of $26 \%$.
\end{abstract}

These results were very promising and the experiment was replicated with a new group of students in grades 3-5 participating in Energy Clubs at the same two elementary schools with the same goal [to reject the null hypothesis: Hands-on engineering activities during GK-12 outreach administered Energy Clubs do not result in a better understanding of technology, what engineers do, the engineering design process, or how to improve a windmill.] The results the second time were approximately equally positive with improvements ranging from $4 \%$ to $8 \%$ in their understanding of technology, what engineers do and the engineering design process with the greatest overall improvement in understanding how to improve a windmill at 16\%. The 2010 data proved to be statistically significant in three of the four categories: "What do engineers do?" $(\mathrm{t}=-2.240$, 77 df, $\mathrm{p}<0.05)$, "Engineering Design Process $(\mathrm{t}=-2.013,77 \mathrm{df}, \mathrm{p}<0.05)$ and "How to improve a windmill" ( $\mathrm{t}=-2.171,77 \mathrm{df}, \mathrm{p}<0.05)$.

RAMP-UP is a GE Foundation and National Science Foundation funded GK-12 Outreach Program at North Carolina State University and has established Energy Clubs at two, local, inner-city elementary schools for the 2010-2011 school year. A RAMP-UP Graduate Fellow with assistance from Undergraduate Fellows and Teachers facilitates the Energy Clubs. These clubs provide an opportunity for students in grades 3-5 to meet outside of regularly scheduled class time to learn about renewable energy, water purification, energy conservation and recycling. The facilitator utilizes a combination of original activities and Engineering is Elementary activities during the fall semester. The spring semester is spent designing and building solar cars in preparation for the Junior Solar Sprint held on campus in May.

\section{Introduction}

In January of 2007, RAMP-UP, a GE Foundation and National Science Foundation funded GK-12 Outreach Program at the North Carolina State University began its first 
Energy Club at one elementary school. Due to the demand to learn more about renewable energy, RAMP-UP increased the number of Energy Clubs to one club at three different elementary schools by the 2008-2009 school year. For the 2009-2010 academic year, the program installed two clubs, one for fifth graders and one for third and fourth graders combined, at two elementary schools. These clubs are unique for this age group and were created through a collaboration between the RAMP-UP Graduate Fellow and a third grade teacher.

The focus of the club is to use hands-on activities to teach math, science and engineering concepts related to renewable energy. This is in line with Dr. John Dewey, one of the founders of pragmatism in education who believed that learning was active and that math could be learned through everyday activities such as cooking.[1] Building upon this concept, RAMP-UP has created original activities that anyone could recreate in their home to help teach math. For example, one of the Program's most popular activities is the "Marshmallows and Toothpicks Activity" where students build two-dimensional and three-dimensional geometric shapes using marshmallows and toothpicks.

Following a pragmatist approach, it is believed that active learning is a fun and feasible teaching style that replaces words with activities as the means of communicating new concepts. RAMP-UP creates opportunities for active learning through many out of classroom learning experiences such as math clubs, Energy Clubs, tutoring, FAME (Fun Applications in Math and Engineering) and assistance with science fair projects.

Last year, an attempt was made to show how active learning, through RAMP-UP's Energy Clubs, impacts third, fourth and fifth grade students and their understanding of technology, what engineers do, the engineering design process and how to improve a windmill. The results were very promising. After completing one activity where the students built windmills out of milk cartons, there were positive improvements ranging from $3 \%$ to $8 \%$ in their understanding of technology, what engineers do and the engineering design process. Significant gains $(\mathrm{p}<0.05)$ were made in understanding how to improve a windmill where all the clubs had double-digit growth with an overall improvement of $26 \%$.

For this paper we replicated the experiment with a new group of students at the same two elementary schools and gave them the same pretest and posttest from the Engineering is Elementary workbook, "Catching the Wind."[2]. The results were again, positive.

\section{Definitions}

For the purpose of this paper, any use of the word "student" refers to a child in grades 35 , any use of the word "Fellow" refers to an undergraduate or graduate student from North Carolina State University, and any use of the word "teacher" refers to a teacher in a Wake County public school.

The RAMP-UP Fellows work in the primary schools when the university semester is in session, which results in a 12-13 week presence in the schools. The program has had a 
presence in three, inner-city elementary schools and one middle school for the past five years and continues today. This paper focuses on our assistance in two of the elementary schools hereafter referred to as elementary school 1 (ES1) and elementary school 2 (ES2).

\section{The Energy Club}

Energy Clubs provide an opportunity for students in grades 3-5 to meet outside of regularly scheduled class time to learn about renewable energy, water purification, energy conservation and recycling. The Graduate Fellow utilizes a combination of original activities and activities developed by the Engineering is Elementary team of the Boston Museum of Science [2] to teach math, science and engineering concepts.

Since it's conception, the program has increased the number of Energy Clubs from one club at one school the first year to one club at two schools in the second year, and to one club at three schools in the third year. Each club consisted of an even mix of third, fourth and fifth graders. There was a large gap in ability between third and fifth graders and therefore decided to create two separate clubs the fourth year (2009-2010): one for fifth graders and one for third and fourth graders combined at two elementary schools. For the 2010-2011 academic year, six clubs were created at two schools. Each school had a third grade, a fourth grade and a fifth grade club.

The students are recruited through letters taken home to the parents and returned to the teacher coordinator. Students are accepted on a first come, first serve basis into Energy Club. Last year (2009-2010), at one of the elementary schools, over 100 letters were returned within two days and only the first eighteen accepted into the $5^{\text {th }}$ grade club and fifteen in the $3^{\text {rd }}$ and $4^{\text {th }}$ grade club. A similar recruiting process was done at the other elementary school, which resulted in seven students in the $5^{\text {th }}$ grade club and fifteen in the $3^{\text {rd }}$ and $4^{\text {th }}$ grade club. This year $(2010-2011)$, the same recruiting processes were used resulting in 27,15 , and 20 fifth, fourth, and third grade students respectively at one elementary school and 16,14 , and 18 fifth, fourth and third grade students respectively at the second elementary school.

Because of the demand, Energy Club is considered a privilege and attendance is mandatory. Energy Clubs meet weekly for an hour either before school or after school. The students maintain a journal that contains their ideas, designs, data and material learned.

\section{Experiment}

The goal of the experiment will be to reject the null hypothesis: Hands-on engineering activities during GK-12 outreach administered Energy Clubs do not result in a better understanding of: technology, what engineers do, the engineering design process, or how to improve a windmill. 
All students in the six clubs were given a pretest at the first meeting. The test used was the assessment at the back of the Engineering is Elementary workbook, "Catching the Wind." [2] The students were sufficiently spaced to avoid cheating and the test took approximately 30 minutes.

At the second meeting, the students were introduced to the engineering design process (as described in the Engineering is Elementary workbook) and wrote it in their journal. The Graduate Fellow then showed them a prototype of a windmill made from a milk carton, dowel, foam, popsicle sticks and index cards and explained the goal which was to see how quickly they could raise the "bucket" (a Dixie cup) off the floor to the height of the dowel. The students worked individually or in groups of two or three to ask, imagine, and plan (the first three steps of the design process) their windmill. The latter two steps involved drawing their design ideas in their journal and working together to decide which design to build. Once they had sufficiently performed the first three steps of the design process, they were allowed to proceed to the last two steps of the design process, which are creating and improving.

They spent the next three to four weeks building the windmills, testing them and improving their speed. The number, shape and size of the blades evolved over time. All the teams went through each step of the design process numerous times. One of the first teams to successfully raise the bucket did so on their thirteenth try. At the end of four weeks, the fastest time recorded was 2.88 seconds by a fourth grader. Surprisingly, no one tired of trying to improve the windmill each week in order to beat the fastest time. At the last meeting, the students were given the posttest, which was the same as the pretest.

\section{Data}

Table 1 lists the sample size of the data from each club. There were more students in each club however, due to schedules or weather, only the below numbers of students took both the pretest and the posttest. 
Table 1: Sample Sizes

\begin{tabular}{|l|l|l|}
\hline Year & & Sample Size \\
\hline 2009 & ES1 $5^{\text {th }}$ Grade & 12 \\
\hline & ES1 $^{\text {rd }}$ and $4^{\text {th }}$ Grade & 13 \\
\hline & ES2 $5^{\text {th }}$ Grade & 6 \\
\hline & ES2 $3^{\text {rd }}$ and $4^{\text {th }}$ Grade & 12 \\
\hline & Average Overall Change & 43 \\
\hline 2010 & ES1 $5^{\text {th }}$ Grade & 19 \\
\hline & ES1 $4^{\text {th }}$ Grade & 8 \\
\hline & ES1 $^{\text {rd }}$ Grade & 16 \\
\hline & ES2 $^{\text {th }}$ Grade & 9 \\
\hline & ES2 $4^{\text {th }}$ Grade & 11 \\
\hline & ES2 $3^{\text {rd }}$ Grade & 15 \\
\hline & Total & 78 \\
\hline
\end{tabular}

Table 2 lists the average score for each Energy Club on the first two questions of the assessment. The maximum possible score on both problems is sixteen. For the first question, "What is Technology?" the students were presented with pictures of sixteen objects and they had to circle the ones they thought were technology. The second question, "What do Engineers do?" consisted of pictures of sixteen actions and they had to circle the ones showing the work that engineers do.

Table 2: What is technology? What do engineers do?

\begin{tabular}{|l|l|l|l|l|l|}
\hline Year & & What is Technology? & & What do Engineers do? & \\
\hline & & Pre & Post & Pre & Post \\
\hline 2009 & ES1 $^{\text {th }}$ Grade & 10 & 10 & 7 & 8 \\
\hline & ES1 $3^{\text {rd }}$ and $4^{\text {th }}$ Grade & 9 & 9 & 8 & 7 \\
\hline & ES2 $5^{\text {th }}$ Grade & 10 & 11 & 8 & 9 \\
\hline & ES2 $3^{\text {rd }}$ and $4^{\text {th }}$ Grade & 9 & 9 & 6 & 7 \\
\hline 2010 & ES1 $5^{\text {th }}$ Grade & 11 & 11 & 9 & 10 \\
\hline & ES1 $4^{\text {th }}$ Grade & 11 & 10 & 10 & 11 \\
\hline & ES1 $3^{\text {rd }}$ Grade & 9 & 9 & 8 & 8 \\
\hline & ES2 $5^{\text {th }}$ Grade & 10 & 11 & 8 & 7 \\
\hline & ES2 $4^{\text {th }}$ Grade & 9 & 10 & 7 & 9 \\
\hline & ES2 $3^{\text {rd }}$ Grade & 9 & 9 & 7 & 7 \\
\hline
\end{tabular}

There were five multiple-choice questions that assessed their knowledge of the design process. Each question was marked as either correct or incorrect. Table 3 shows the percentage of the class getting each multiple-choice question correct. 
Table 3: Knowledge of the engineering design process

\begin{tabular}{|c|c|c|c|c|c|c|c|c|c|c|c|}
\hline & & Pre & & & & & Post & & & & \\
\hline Year & $\begin{array}{l}\text { Question } \\
\#\end{array}$ & 1 & 2 & 3 & 4 & 5 & 1 & 2 & 3 & 4 & 5 \\
\hline \multirow[t]{4}{*}{2009} & $\mathrm{ES} 15^{\text {th }}$ & $33 \%$ & $100 \%$ & $42 \%$ & $25 \%$ & $75 \%$ & $83 \%$ & $92 \%$ & $58 \%$ & $58 \%$ & $92 \%$ \\
\hline & $\begin{array}{l}\text { ES1 } 3^{\text {rd }} \\
\text { and } 4^{\text {th }}\end{array}$ & $54 \%$ & $62 \%$ & $77 \%$ & $69 \%$ & $77 \%$ & $62 \%$ & $92 \%$ & $62 \%$ & $46 \%$ & $85 \%$ \\
\hline & $\mathrm{ES} 25^{\text {th }}$ & $100 \%$ & $83 \%$ & $67 \%$ & $50 \%$ & $83 \%$ & $50 \%$ & $83 \%$ & $33 \%$ & $50 \%$ & $100 \%$ \\
\hline & $\begin{array}{l}\text { ES2 } 3^{\text {rd }} \\
\text { and } 4^{\text {th }}\end{array}$ & $42 \%$ & $100 \%$ & $33 \%$ & $42 \%$ & $67 \%$ & $58 \%$ & $92 \%$ & $33 \%$ & $42 \%$ & $58 \%$ \\
\hline \multirow[t]{6}{*}{2010} & ES1 $5^{\text {th }}$ & $37 \%$ & $95 \%$ & $47 \%$ & $63 \%$ & $74 \%$ & $63 \%$ & $100 \%$ & $53 \%$ & $47 \%$ & $95 \%$ \\
\hline & ES1 $4^{\text {th }}$ & $40 \%$ & $53 \%$ & $7 \%$ & $13 \%$ & $20 \%$ & $27 \%$ & $53 \%$ & $33 \%$ & $33 \%$ & $47 \%$ \\
\hline & $\mathrm{ES} 13^{\text {rd }}$ & $50 \%$ & $75 \%$ & $38 \%$ & $19 \%$ & $63 \%$ & $56 \%$ & $88 \%$ & $44 \%$ & $31 \%$ & $69 \%$ \\
\hline & ES2 $5^{\text {th }}$ & $67 \%$ & $89 \%$ & $67 \%$ & $67 \%$ & $89 \%$ & $67 \%$ & $67 \%$ & $33 \%$ & $33 \%$ & $78 \%$ \\
\hline & $\mathrm{ES} 24^{\text {th }}$ & $64 \%$ & $100 \%$ & $55 \%$ & $55 \%$ & $73 \%$ & $91 \%$ & $100 \%$ & $36 \%$ & $36 \%$ & $73 \%$ \\
\hline & $\mathrm{ES} 23^{\text {rd }}$ & $47 \%$ & $87 \%$ & $27 \%$ & $27 \%$ & $60 \%$ & $73 \%$ & $100 \%$ & $40 \%$ & $20 \%$ & $87 \%$ \\
\hline
\end{tabular}

Table 4 shows the results when asked how to improve your windmill. The maximum possible score is 4

Table 4: How to improve your windmill

\begin{tabular}{|l|l|l|l|}
\hline Year & & Pre & Post \\
\hline 2009 & ES1 $^{\text {th }}$ Grade & 2.25 & 2.92 \\
\hline & ES1 3 $^{\text {rd }}$ and 4 & th \\
\hline & ES2 $5^{\text {th }}$ Grade & 2.23 & 2.62 \\
\hline & ES2 $3^{\text {rd }}$ and 4 & 2.33 & 3.00 \\
\hline 2010 & ES1 $^{\text {th }}$ Grade & 2.33 & 3.00 \\
\hline & ES1 $^{\text {th }}$ Grade & 2.79 & 3.00 \\
\hline & ES1 3 ${ }^{\text {rd }}$ Grade & 2.13 & 3.00 \\
\hline & ES2 $5^{\text {th }}$ Grade & 1.75 & 2.00 \\
\hline & ES2 $4^{\text {th }}$ Grade & 2.78 & 2.44 \\
\hline & ES2 $3^{\text {rd }}$ Grade & 2.36 & 2.73 \\
\hline
\end{tabular}




\section{Analysis}

The percent changes from the pretest to the posttest are presented in Tables 5-7.

Table 5: What is technology? What do engineers do?

\begin{tabular}{|c|c|c|c|}
\hline & & $\begin{array}{l}\text { What is } \\
\text { technology? }\end{array}$ & $\begin{array}{l}\text { What do engineers } \\
\text { do? }\end{array}$ \\
\hline Year & & $\%$ Change & $\%$ Change \\
\hline \multirow[t]{5}{*}{2009} & ES1 $5^{\text {th }}$ Grade & 0 & 14 \\
\hline & ES1 $3^{\text {rd }}$ and $4^{\text {th }}$ Grade & 0 & -13 \\
\hline & ES2 $5^{\text {th }}$ Grade & 10 & 13 \\
\hline & ES2 $3^{\text {rd }}$ and $4^{\text {th }}$ Grade & 0 & 17 \\
\hline & Average Overall Change & 3 & 8 \\
\hline \multirow[t]{7}{*}{2010} & ES1 $5^{\text {th }}$ Grade & 0 & 9 \\
\hline & ES1 $4^{\text {th }}$ Grade & -9 & 14 \\
\hline & ES1 $3^{\text {rd }}$ Grade & -1 & 2 \\
\hline & ES2 $5^{\text {th }}$ Grade & 16 & -7 \\
\hline & ES2 $4^{\text {th }}$ Grade & 16 & 25 \\
\hline & ES2 $3^{\text {rd }}$ Grade & 3 & 8 \\
\hline & Average Overall Change & 4 & 8 \\
\hline
\end{tabular}

Table 6: Knowledge of the engineering design process

\begin{tabular}{|l|l|l|}
\hline Year & & \% Improvement per club \\
\hline 2009 & ES1 $^{\text {th }}$ Grade & 39 \\
\hline & ES1 $3^{\text {rd }}$ and $4^{\text {th }}$ Grade & 2 \\
\hline & ES2 $5^{\text {th }}$ Grade & -17 \\
\hline & ES2 $^{\text {rd }}$ and $4^{\text {th }}$ Grade & 0 \\
\hline & Average Overall Change & 6 \\
\hline & ES1 $5^{\text {th }}$ Grade & 12 \\
\hline & ES1 $4^{\text {th }}$ Grade & 31 \\
\hline & ES1 $3^{\text {rd }}$ Grade & 15 \\
\hline & ES2 $5^{\text {th }}$ Grade & -36 \\
\hline & ES2 $4^{\text {th }}$ Grade & -3 \\
\hline & ES2 $3^{\text {rd }}$ Grade & 23 \\
\hline & Average Overall Change & 6 \\
\hline
\end{tabular}


Table 7: How to improve your windmill.

\begin{tabular}{|l|l|l|}
\hline Year & & \% Change \\
\hline 2009 & ES1 $^{\text {th }}$ Grade & 30 \\
\hline & ES1 $^{\text {rd }}$ and $4^{\text {th }}$ Grade & 17 \\
\hline & ES2 $5^{\text {th }}$ Grade & 29 \\
\hline & ES2 $3^{\text {rd }}$ and $4^{\text {th }}$ Grade & 29 \\
\hline & Average Overall Change & 26 \\
\hline 2010 & ES1 $5^{\text {th }}$ Grade & -12 \\
\hline & ES1 $4^{\text {th }}$ Grade & 15 \\
\hline & ES1 $3^{\text {rd }}$ Grade & 27 \\
\hline & ES2 $5^{\text {th }}$ Grade & 8 \\
\hline & ES2 $4^{\text {th }}$ Grade & 41 \\
\hline & ES2 $3^{\text {rd }}$ Grade & 14 \\
\hline & Average Overall Change & 16 \\
\hline
\end{tabular}

A statistical analysis was performed on the data. The pretest and posttest scores were compared for the individual students giving a total sample size of 43 in 2009 and 78 in 2010. The results of the paired t-test analysis are listed in Table 8.

Table 8: Paired t-test analysis

\begin{tabular}{|l|l|l|l|l|l|l|l|}
\hline Year & Question & Test & Mean & $\begin{array}{l}\text { SE } \\
\text { Mean }\end{array}$ & $\mathrm{t}$ & $\mathrm{df}$ & $\mathrm{p}$ \\
\hline 2009 & What is technology? & Pre & 9.51 & 0.33 & 0.844 & 42 & 0.404 \\
\hline & & Post & 9.30 & 0.28 & & & \\
\hline & What do engineers do? & Pre & 7.28 & 0.36 & -1.172 & 42 & 0.248 \\
\hline & & Post & 7.70 & 0.43 & & & \\
\hline & Engineering design process & Pre & 3.12 & 0.20 & -1.044 & 42 & 0.303 \\
\hline & & Post & 3.35 & 0.20 & & & \\
\hline & How to improve your windmill. & Pre & 2.28 & 0.14 & -3.411 & 42 & 0.001 \\
\hline & & Post & 2.86 & 0.13 & & & \\
\hline 2010 & What is technology? & Pre & 9.63 & 0.30 & -1.047 & 77 & 0.298 \\
\hline & & Post & 9.94 & 0.32 & & & \\
\hline & What do engineers do? & Pre & 8.15 & 0.32 & -2.240 & 77 & 0.028 \\
\hline & & Post & 8.81 & 0.32 & & & \\
\hline & Engineering design process & Pre & 2.92 & 0.16 & -2.013 & 77 & 0.048 \\
\hline & & Post & 3.27 & 0.14 & & & \\
\hline & How to improve your windmill. & Pre & 2.29 & 0.12 & -2.171 & 77 & 0.033 \\
\hline & & Post & 2.60 & 0.12 & & & \\
\hline
\end{tabular}

In the 2009 group, of the four questions, only "How to improve your windmill" was statistically significant with a pretest mean $=2.28$ and standard error of the mean $=0.14$, and a posttest mean $=2.86$ and standard error of the mean $=0.13$. This gave a t of -3.411 
with 42 degrees of freedom and p-value less than .05. The 2010 data proved to be statistically significant in three of the four categories: "What do engineers do?" $(\mathrm{t}=-2.240$, 77 degrees of freedom, $\mathrm{p}<0.05)$, "Engineering Design Process $(\mathrm{t}=-2.013,77$ degrees of freedom, $\mathrm{p}<0.05)$ and "How to improve a windmill" ( $\mathrm{t}=-2.171,77$ degrees of freedom, $\mathrm{p}$ $<0.05)$.

\section{Conclusions}

Overall, there were positive improvements in their understanding of technology, what engineers do, the engineering design process and how to improve their windmill just from having performed one activity over a period of several weeks for all clubs. In 2009 and 2010 , their understanding of technology improved by $3 \%$ and $4 \%$ respectively, what an engineer does by $8 \%$ and the engineering design process by $6 \%$ in both years.

Unfortunately, none of these three improvements were statistically significant in 2009 but there were significant gains $(\mathrm{p}<0.05)$ in understanding what engineers do, and the engineering design process in 2010, which leads one to conclude that more data should be acquired to confirm this finding. There were significant gains $(p<0.05)$ in understanding how to improve a windmill in both 2009 and 2010. All the groups had double-digit growth with an overall improvement of $26 \%$ in 2009 and $16 \%$ in 2010.

\section{Table 9: Null Hypothesis: Reject or Fail to Reject per year}

\begin{tabular}{|l|l|l|}
\hline $\begin{array}{l}\text { Hands-on engineering activities during GK-12 } \\
\text { outreach administered Energy Clubs do not } \\
\text { result in a better understanding of: }\end{array}$ & 2009 & 2010 \\
\hline Technology & Fail to Reject & Fail to Reject \\
\hline What engineers do & Fail to Reject & Reject $(\mathrm{p}<0.05)$ \\
\hline The engineering design process & Fail to Reject & Reject $(\mathrm{p}<0.05)$ \\
\hline How to improve a windmill & Reject $(\mathrm{p}<0.05)$ & Reject $(\mathrm{p}<0.05)$ \\
\hline
\end{tabular}

With a $\mathrm{p}<0.05$, there is a significant difference between the means of the pretests and posttests and one can reject the null hypothesis and therefore conclude that active learning during out-of-school time Energy Clubs, can positively affect students in grades 3-5 by improving their ability to improve a windmill two years in a row.

It is promising to see such positive results based on performing one activity. One can see that active learning during out-of-school time Energy Clubs, can positively affect students in grades 3-5. 


\section{References and Footnotes}

[1] Neill, J. (2005). John Dewey: Philosophy of Education. Retrieved Jan. 5, 2010, from Outdoor Education Research \& Evaluation Center, New Hampshire. Web site:

http://wilderdom.com/experiential/JohnDeweyPhilosophyEducation.html.

[2] Cunningham, C. M. (2010). Engineering Is Elementary. Retrieved Jan. 5, 2010, from Engineering is Elementary, Boston, MA. Web site: http://www.mos.org/eie/index.php. 
Appendix: Excerpts of the Engineering is Elementary Assessment from "Catching the Wind" [2]

\section{What is Technology?}

Which of these things are examples of technology?

Circle all of the items that you think are technology.

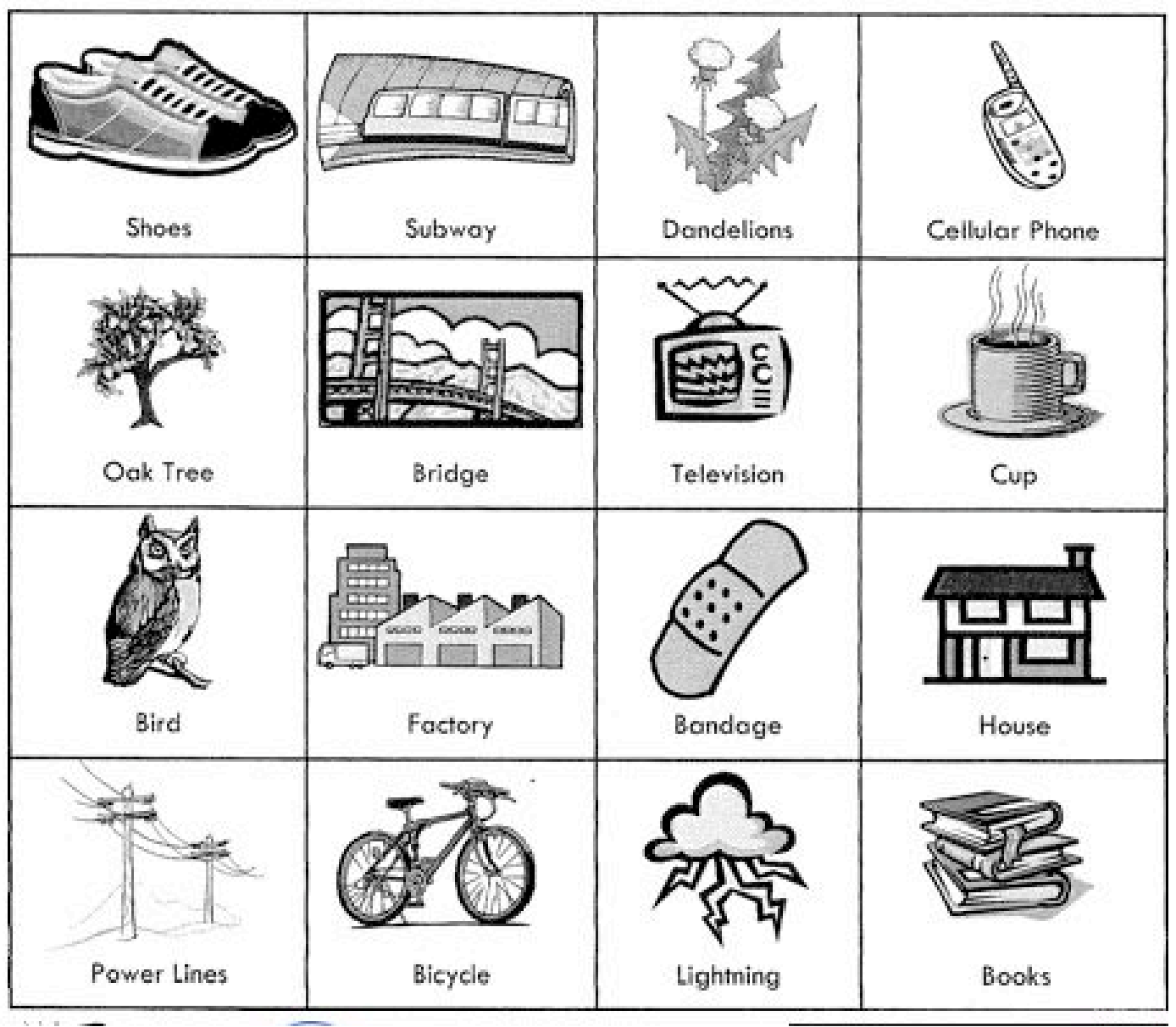

Figure 1: Question 1: What is Technology? 


\section{What is an Engineer?}

What kinds of work do engineers do?

Circle the kinds of work that you think engineers do for their jobs.

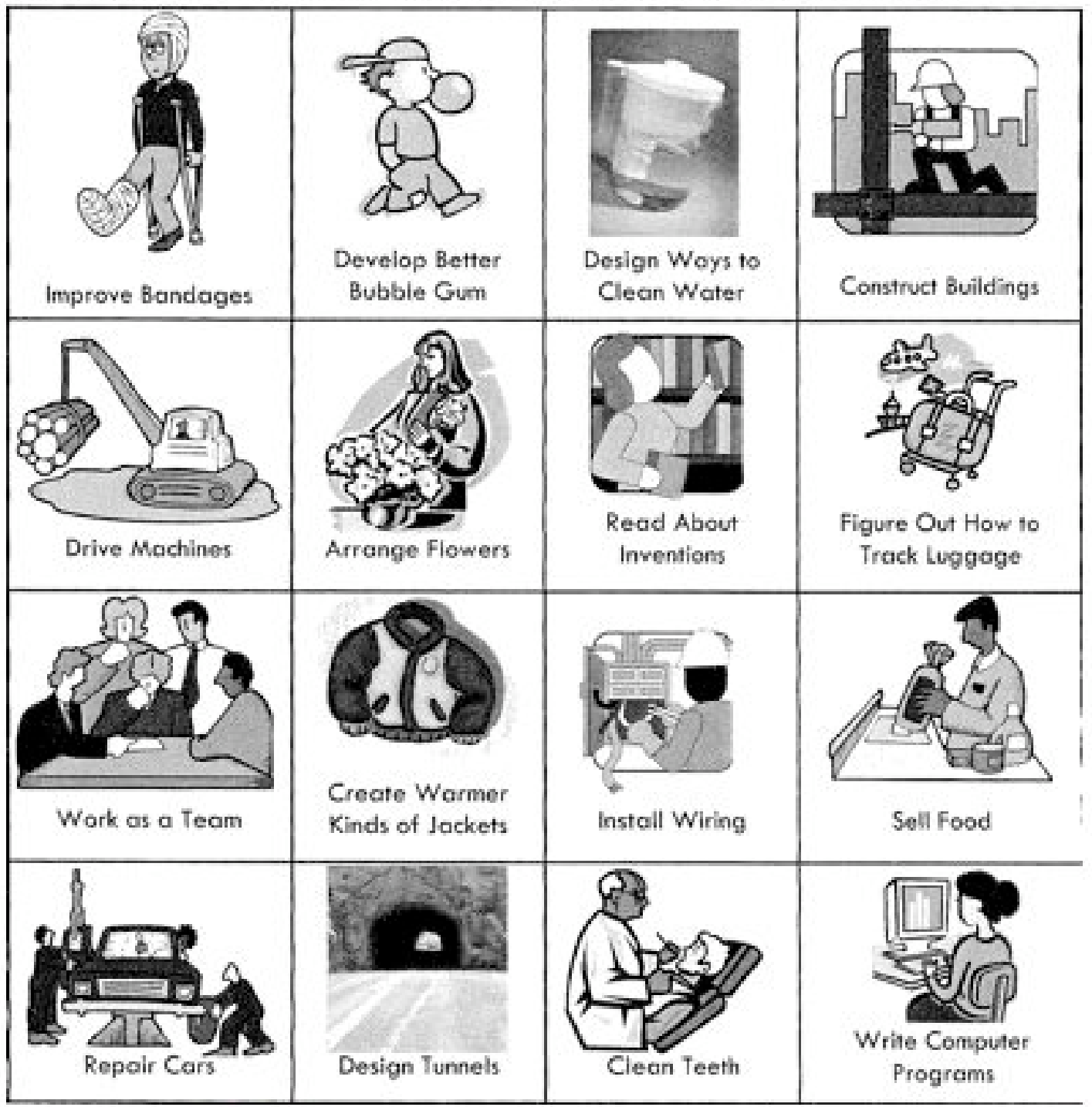

Figure 2: Question 2: What is an Engineer? What kinds of work do engineers do? 
1. David and Sonali are working on a design. They are making this list. Which step of the engineering design process are they working on? Circle ONE answer.
A. Ask
B. Plan
C. Create
D. Improve

\section{Correct or Incorrect}
5 questions

Things we could do to make our assembly line work faster:

1. Make the lever longer

2. Put the simple machines closer together

3. Attach another bucket to the cart

Figure 3: One of the questions regarding the design process

1. Shara is making a windmill, but cannot make it spin. She makes the blades bigger, but it still does not spin. Check ALL of the things that she might do next to improve her windmill.
$\square \quad$ Add more blades
$\square$ Put holes in the blades to let air through
$\square$ Change the material the blades are made of.
$\square \quad$ Change the angle of the blades.

Figure 4: Question regarding how to improve a windmill 